\title{
Current Views on Noninvasive in vivo Determination of Physiological Parameters of the Stratum Corneum Using Confocal Raman Microspectroscopy
}

\author{
Maxim E. Darvin ${ }^{\mathrm{a}}$ Johannes Schleusener ${ }^{\mathrm{a}}$ Jürgen Lademann ${ }^{\mathrm{a}}$ \\ Chun-Sik Choe ${ }^{\text {b }}$
}

aDepartment of Dermatology, Venerology and Allergology, Center of Experimental and Applied Cutaneous Physiology (CCP), Charité - Universitätsmedizin Berlin, Corporate Member of Freie Universität Berlin and

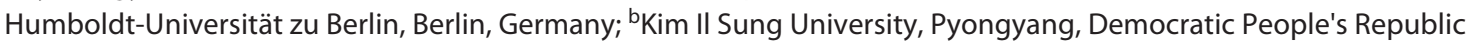
of Korea

\section{Keywords}

Skin barrier function $\cdot$ Intercellular lipids $\cdot$ Keratin $\cdot$ Water mobility · Skin hydration cal Raman microspectroscopy in noninvasive investigation of the skin and summarizes recent results on in vivo investigation of the human SC.

(c) 2022 S. Karger AG, Basel

\begin{abstract}
Confocal Raman microspectroscopy is widely used in dermatology and cosmetology for analysis of the concentration of skin components (lipids, natural moisturizing factor molecules, water) and the penetration depth of cosmetic/medical formulations in the human stratum corneum (SC) in vivo. In recent years, it was shown that confocal Raman microspectroscopy can also be used for noninvasive in vivo depth-dependent determination of the physiological parameters of the SC, such as lamellar and lateral organization of intercellular lipids (ICLs), folding properties of keratin, water mobility, and hydrogen bonding states. The results showed that the strongest skin barrier function, which is primarily manifested by the orthorhombic organization of ICLs, is provided at $\approx 20-40 \%$ SC depth, which is related to the maximal bonding state of water with surrounding components in the SC. The secondary and tertiary structures of keratin determine water binding in the SC, which is depth-dependent. This paper shows the technical possibility and advantage of confo-
\end{abstract}

\section{Introduction}

The stratum corneum (SC), the outermost layer of the epidermis, consists of enucleated cells - corneocytes embedded into the intercellular lipid (ICL) matrix and serves as initial barrier against penetration of xenobiotics into the skin [1]. Compared to other cellular types, corneocytes are stiff cells [2] and consist mainly of keratin filaments, natural moisturizing factor (NMF) molecules, and water, surrounded by inner protein and outer lipid envelopes $[3,4]$. Corneocytes contribute to the skin barrier function [2] and represent an effective barrier to xenobiotics.

Keratin is the main fibrillar protein that forms the cytoskeleton of corneocytes and is involved in providing the skin barrier function. Keratin is characterized by strength and insolubility in water and salt solutions due to the presence of a large number of disulfide bonds (covalent
Karger@karger.com www.karger.com/spp
(C) 2022 S. Karger AG, Basel

Karger!"
Correspondence to:

Maxim E. Darvin, maxim.darvin@ charite.de 
bonds between the sulfur atoms of the sulfur-containing amino acid cysteine) between the peptide chains in its structure. Keratin synthesis begins in the basal layer of the epidermis, where in keratinocytes, the low molecular weight prekeratin has no disulfide bonds. During the proliferation of keratinocytes, due to the action of specific enzymes, prekeratin "matures" in the lower regions of the SC and turns into mature keratin [5], characterized by the presence of disulfide bonds. The SC contains so-called soft keratin, which has a low concentration of sulfur-containing amino acids $(\approx 2-3 \%)$. The concentration of keratin and ICL is nonhomogeneously distributed throughout the SC and increases from the bottom toward the uppermost SC depths [6].

The ICLs in the SC are released from lamellar granules of the stratum granulosum [7] and form lamellas, where lipids (mainly ceramides, free fatty acids, and cholesterol [8]) are bound to each other and form the entire membrane-like lamellar structure [9-11]. The nonpolar hydrophobic tails of lipid molecules are connected to each other forming a common hydrophobic central zone of the membrane that is not in contact with water, while polar hydrophilic lipid heads form the periphery of the membrane, which is directed toward the water environment $[12,13]$, forming a heterogeneous layered structure inside the lamellae. It has been shown that ICL forms a threelayer lamellar structure, consisting of alternating lipid bilayers defining "broad-narrow-broad" segments [14-18], which are known as long $(\approx 13.4 \mathrm{~nm})$ and short $(\approx 6.4 \mathrm{~nm})$ periodicity phases $[15,18,19]$. There is also an opinion that the thicknesses of all lipid layers inside the lamellae are identical and are characterized only by a short periodicity phase with a distance of $\approx 4.2-4.8 \mathrm{~nm}[10,17,20,21]$. Another model is based on the presence of an asymmetric lamellar phase within the ICL matrix with a distance of $\approx 11 \mathrm{~nm}$, which is a combination of two phases of 4.5 and $6.5 \mathrm{~nm}[10,22]$. The presence of three-layer segments with distances of $11.5,6.0$, and $4.5 \mathrm{~nm}$ was also observed in vitro analyzing human SC using small-angle and wideangle X-ray scattering [23]. The exact lamellar organization of the SC's ICL matrix is still debated, and there is no consensus on exact understanding of how ceramides, cholesterol, free fatty acids, and other substances are linked together in an ICL membrane. Thus, lipids inside the ICL matrix are strictly structured inside lamellas and are oriented, mainly, perpendicular to the skin surface [11], which directly determines their lateral organization and, consequently, the skin barrier function [19, 24, 25]. The lateral organization of the ICL matrix contains orthorhombic (ordered, very densely packed lipids) and hexagonal (ordered, less densely packed lipids) phases, which are nonhomogeneously distributed in the SC depth $[23,26]$. Using the $\mathrm{x}$-ray diffraction method in in vitro and ex vivo experiments, a predominant content of the orthorhombic phase was observed at a depth of $\approx 35-50 \%$ of the SC thickness. The presence of orthorhombic lateral organization of ICL determines the skin barrier function provided by the SC [27]. As in vivo measurements are not possible, the skin sample preparation protocol may significantly affect the morphology of the ICL lamellas and should be considered in studies [10,22]. Quatela et al. [28] support this statement, showing that the separation of SC leads to a decrease in the skin barrier function, i.e., the sample preparation procedure has an effect on the integrity of ICL lamellas.

Water plays a decisive role in the physiological functioning of the skin. The epidermis contains $\approx 30 \%$ of the water in the skin. The SC is the most dehydrated epidermal layer and contains $\approx 15 \%$ of all water in the epidermis. Water serves as a medium for action of numerous enzymes that make the SC metabolically active. The lack of water in the SC is called dry skin and leads to the disruption of the skin barrier function and SC integrity and is often associated with skin diseases, such as atopic dermatitis or psoriasis [29-31]. The lipid loss can cause marked increases in drying of the SC $[32,33]$. Thus, the SC hydration is an important physiological parameter of healthy skin, which is indirectly influencing the skin barrier function. Water is nonhomogeneously distributed throughout the SC and has minimal concentration at the superficial SC depth and highest concentration at the bottom SC depth, close to the boundary to the stratum granulosum [34]. The binding properties of water in the SC are dependent on the concentration of binding centers, such as keratin [35], NMF molecules [36], and ICLs [37], whose distribution is nonhomogeneous throughout the SC [38] and is age dependent $[39,40]$. The mobility of water molecules and interaction of water with surrounding molecules are of high interest in dermatology and cosmetology. Analysis of skin hydration should be preferably performed noninvasively and in vivo due to the quick evaporation of water from skin biopsy samples.

In noninvasive investigation of the SC in vivo, imaging methods, such as confocal laser scanning microscopy, optical coherence tomography, and two-photon tomography are used mainly for determination of the SC thickness, SC's surface appearance and to determine penetration depth of topically applied substances [41-44]. These methods are based on the measurement of fluorescence and reflectance of the SC and are not sensitive to the 


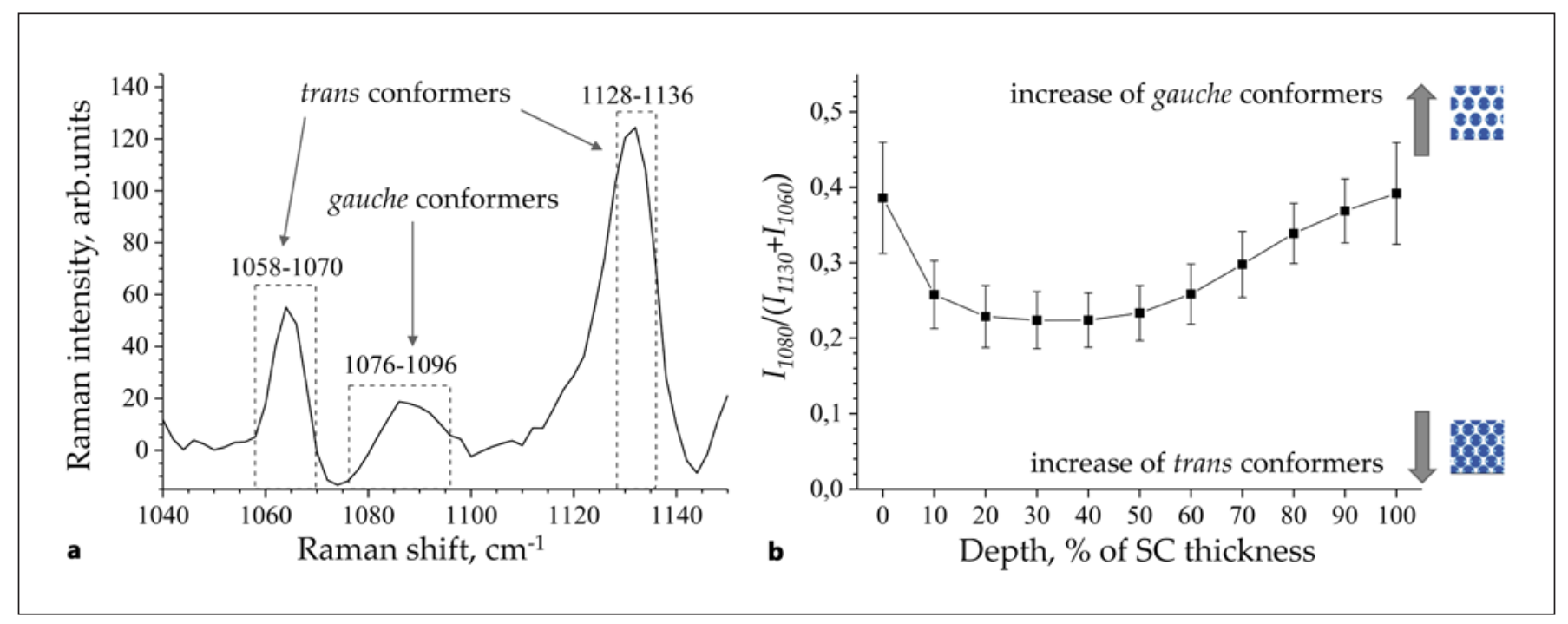

Fig. 1. Typical Raman spectrum of human SC (depth $4 \mu \mathrm{m}$ ) in the $1,040-1,150 \mathrm{~cm}^{-1}$ region post noise reduction procedure using principal component analysis with appropriate integration areas (a); the mean SC depth profile of the gauche-trans conformation order of ICL measured in vivo as a $I_{1,080} /\left(I_{1,130}+I_{1,060}\right)$ ratio (b). The SC thickness is normalized to $100 \%$ ( $0 \%$ - surface, $100 \%$ - bottom of the SC). Figures adopted from [54]. The two colored figures in $\mathbf{b}$ indicate more or less ordered lateral structure of ICL in the SC.

chemical composition of SC components. To date, Raman spectroscopy can be considered one of the most effective and informative noninvasive analytical methods for obtaining information on the chemical composition of substances, conformational order, packing, and orientation of molecules, which makes it advantageous in in vivo investigation of the SC, viable epidermis, and dermis. It was shown on skin biopsies that Raman spectroscopy is a perspective optical noninvasive method in analyzing keratin's secondary and tertiary structures [45], ICL ordering [46-49], and water mobility states [48]. These results showed the potential for direct structural depth analysis of SC components by Raman microspectroscopy in vivo. Recent development of algorithms for analysis of Raman spectra confirms the applicability of confocal Raman microspectroscopy for in vivo determination of barrier function-related physiological parameters of the human SC, such as lamellar and lateral organization of ICL, folding of keratin, water mobility, and hydrogen bonding states, which is presented in this paper.

\section{Results}

\section{Lamellar Organization of Intercellular Lipids}

As shown in the literature $[47,48,50,51]$, three Raman bands at $1,060,1,080$, and $1,130 \mathrm{~cm}^{-1}$ describing the C-C skeleton stretching vibrations of long-chain hydrocarbons are sensitive to the trans-gauche conformation order in lipids. The bands at 1,060 and $1,130 \mathrm{~cm}^{-1}$ appear in the Raman spectrum if the presence of trans-sequences is more than 6 and the length of a long alkyl chains contain more than $18 \mathrm{CH}_{2}$ groups, respectively [52, 53]. With a smaller number of $\mathrm{CH}_{2}$ groups in the trans-sequence, the position of the Raman band at $1,130 \mathrm{~cm}^{-1}$ is shifted toward larger wavenumbers [53]. Thus, Raman bands at 1,060 and $1,130 \mathrm{~cm}^{-1}$ characterize the lipid chains containing trans conformers (more ordered state), while the Raman band at $1,080 \mathrm{~cm}^{-1}$ characterizes the lipid chains containing only gauche conformers (less ordered state). During the transition from more ordered to less ordered structure of lipids, the shape of the Raman band at 1,060 $\mathrm{cm}^{-1}$ undergoes changes: its width and intensity decreases. The shape of the Raman band at $1,080 \mathrm{~cm}^{-1}$ also changes: its width and intensity increase, and the position of the maximum shifts toward shorter wavenumbers [52]. The typical Raman spectrum of human's SC measured in vivo in the $1,040-1,150 \mathrm{~cm}^{-1}$ region is presented in Figure 1a, where the dotted areas show the boundaries used for calculation of lipid-related band intensities.

To describe the influence of surrounding humidity on conformational changes in human ICL ex vivo, Vyumvuhore et al. [48] used the $\left(I_{1,130}+I_{1,060}\right) / I_{1,080}$ ratio of Raman band intensities. Since the Raman band intensity at 

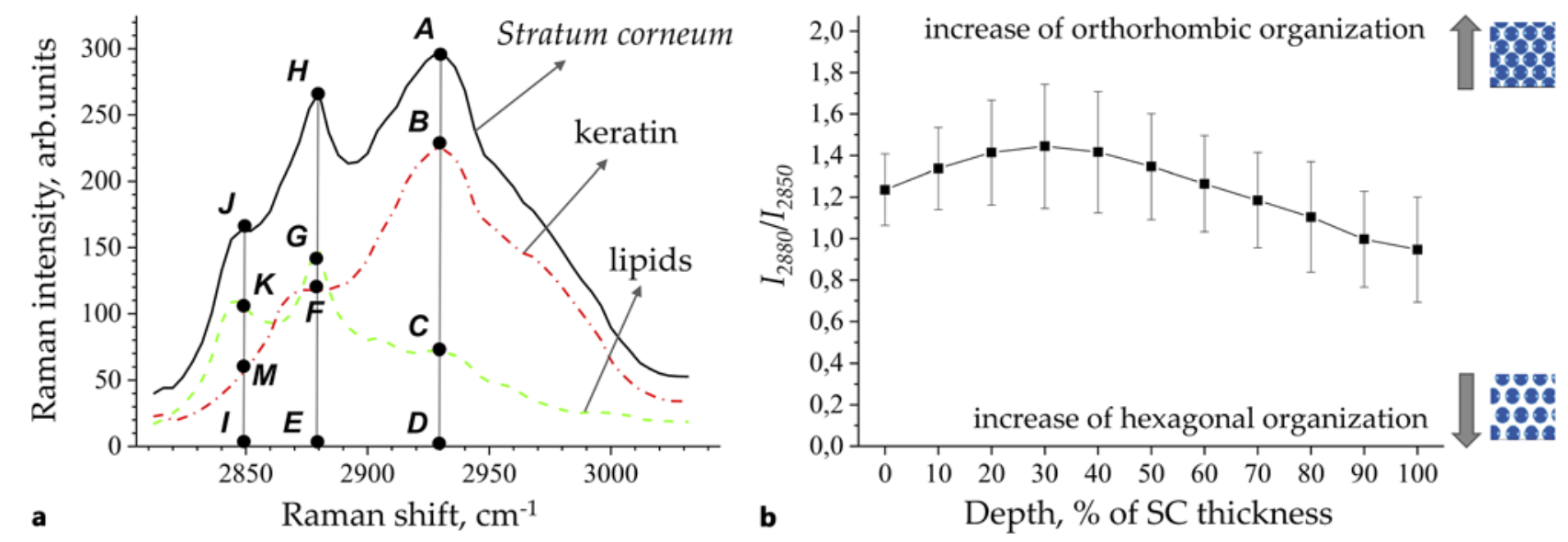

Fig. 2. Raman spectrum of human SC (depth $4 \mu \mathrm{m}$ ) in vivo (solid line), which contains a contribution of lipids (dashed green line) and keratin (dash-dotted red line) (a); the depth profile of the lateral organization of ICL in the SC (b), measured as $I_{2,880} / I_{2,850}(G E / K I$ ratio in $(\mathbf{a}))$ obtained in vivo in the skin of 6 volunteers (mean $\left.\pm S D\right)$. The SC thickness is normalized to $100 \%$ ( $0 \%$ - surface, $100 \%$ - bottom of the SC). Figures adopted from [54]. The two colored figures in $\mathbf{b}$ indicate more or less ordered lateral structure of ICL in the SC.

$1,080 \mathrm{~cm}^{-1}$ is significantly lower than the sum of Raman band intensities at 1,060 and $1,130 \mathrm{~cm}^{-1}$ in the SC, Choe et al. [54] have used an inverse $I_{1,080} /\left(I_{1,130}+I_{1,060}\right)$ ratio to reduce the magnitude of the standard deviation. Thus, the higher value of the $I_{1,080} /\left(I_{1,130}+I_{1,060}\right)$ ratio characterizes ICL with a greater number of gauche conformers in the lipid chains, i.e., a less ordered lamellar organization of ICL. A smaller value of the $I_{1,080} /\left(I_{1,130}+I_{1,060}\right)$ ratio characterizes ICL with a greater number of trans conformers in the lipid chain, i.e., a more ordered lamellar organization of ICL.

The depth profile of the lamellar organization of ICL is presented in Figure $1 \mathrm{~b}$ and shows a nonhomogeneous distribution: the $I_{1,080} /\left(I_{1,130}+I_{1,060}\right)$ ratio decreases from its maximal initial value (highest content of gauche conformers in the lipid chains) on the skin surface to a minimum value (highest content of trans conformers in the lipid chains) at a depth of $20-50 \%$ of the SC thickness. Further, there is a monotonic increase of $I_{1,080} /\left(I_{1,130}+\right.$ $I_{1,060}$ ) ratio at the boundary of the SC and the stratum granulosum, i.e., an increase of the content of gauche conformers in the lipid chains. Thus, the most ordered lamellar organization of the ICL in the SC is observed at a depth of $\approx 20-50 \%$ of SC thickness, while it is less ordered at the surface and at a boundary between SC and stratum granulosum [54].

\section{Lateral Organization of Intercellular Lipids}

The Fourier-transform infrared spectroscopy method can be used to directly measure the lateral organization of ICL in vivo [55], but due to the high absorption of excitation and Raman radiation by water, measurements are limited to the superficial SC depths [49]. The ratio of Raman band intensities at 2,880 $\mathrm{cm}^{-1}$ (antisymmetric stretching mode of $\mathrm{CH}_{2}$ groups) and $2,850 \mathrm{~cm}^{-1}$ (symmetric stretching mode of $\mathrm{CH}_{2}$ groups) $I_{2,880} / I_{2,850}$ depends on the degree of lipid organization, i.e., the transition from crystalline to amorphous states [56, 57]. Gaber and Peticolas [46] studied a mixture of hexadecan $\left(\mathrm{C}_{16} \mathrm{H}_{34}\right)$ and deuterated hexadecan $\left(\mathrm{C}_{16} \mathrm{D}_{34}\right)$ and showed that the $I_{2,880} / I_{2,850}$ ratio describes the degree of the lateral organization of lipids. A higher (lower) $I_{2,880} / I_{2,850}$ ratio characterizes an increased content of trans (gauche) conformers in the lipid chains - higher (lower) lateral ordering of lipids in the lamellas. The lateral organization of lipids was determined in pure lipid systems, which does not correspond to the real situation in the skin, where Raman spectra of lipids and keratin are strongly superimposed. The Raman spectra of the human SC and its components keratin and lipids in the 2,810-3,030 $\mathrm{cm}^{-1}$ region are shown in Figure 2a. Since lipids in the SC are mainly in crystalline domains containing hexagonal and orthorhombic organizations [58], the $I_{2,880} / I_{2,850}$ ratio describes the lateral organization of ICL in the SC [51]. The possi- 
bility to determine the lateral organization of ICL in the SC using Raman spectroscopy was shown in vitro on extracted lipids [47]. For correct determination of the lateral organization of ICL in the SC in vivo, it is necessary to separate the lipid and keratin contributions from each other. Decomposition of the Raman spectrum in the $2,810-3,030 \mathrm{~cm}^{-1}$ range does not provide a sufficient separation [59]. Therefore, Choe et al. [54] have developed a new algorithm, which is based on the calculation of the known contributions of lipids and keratin in the Raman spectrum in the $2,810-3,030 \mathrm{~cm}^{-1}$ region, which is schematically presented in Figure 2a.

To determine the lateral organization of ICL in the SC, the mathematical algorithm shown in Equation 1 was proposed [54], where $K_{2,850}=\mathrm{JI} / \mathrm{AD}, K_{2,880}=\mathrm{HE} / \mathrm{AD}$ (parameters directly measured from the skin Raman spectra), and $P_{\mathrm{K}}^{2,850}=\mathrm{MI} / \mathrm{BD}=0.150 \pm 0.025, P_{\mathrm{K}}^{2,880}=\mathrm{FE} / \mathrm{BD}$ $=0.440 \pm 0.024, P_{\mathrm{L}}^{2,850}=\mathrm{KI} / \mathrm{CD}=0.480 \pm 0.031, P_{\mathrm{L}}^{2,880}=$ $\mathrm{GE} / \mathrm{CD}=0.320 \pm 0.026$ (parameters measured on extracted keratin and lipids).

$$
\frac{I_{2,880}}{I_{2,850}}=\frac{\mathrm{GE}}{\mathrm{KI}}=\left(\frac{K_{2,880}-P_{\mathrm{K}}^{2,880}}{1-P_{\mathrm{L}}^{2,880}}\right) \times\left(\frac{1-K_{2,850} P_{\mathrm{L}}^{2,850}}{K_{2,850}-P_{\mathrm{K}}^{2,850}}\right)
$$

Further, using the developed algorithm, the distribution depth profile of the lateral organization of the ICL in the human SC was determined in vivo for the first time (Fig. 2b). A higher (lower) $I_{2,880} / I_{2,850}$ ratio characterizes a higher amount of trans (gauche) conformers in the ICL chains, and thus shows an increase of orthorhombic (hexagonal) packing of ICL [54]. As can be seen in Figure 2b, the ratio of $I_{2,880} / I_{2,850}$ reaches an intermediate value on the surface of the SC. Then, the $I_{2,880} / I_{2,850}$ ratio increases with increasing SC depth and reaches a maximum value (the highest content of the orthorhombic phase of the lateral ICL organization, the most dense and least permeable ICL package) at a depth of $20-40 \%$ of the SC thickness. Further, the $I_{2,880} / I_{2,850}$ ratio decreases and reaches a minimum value (the highest content of the hexagonal phase of the ICL organization, less dense and more permeable ICL packing) in the bottom of the SC.

In older humans, these parameters are changed at exemplary SC depths toward increase of orthorhombic organization at $20-30 \%$ SC depth $(p<0.1$ between 29 y.o. and 50 y.o. age-groups) [39], which was recently confirmed by Rigal et al. [60]. The lipid organization is changed toward decreasing of skin barrier function in the xerosis and atopic skin in vivo [32, 61]. Porcine skin, which is widely used as an ex vivo model of human skin in dermatological research, has more hexagonal organi- zation of ICL at $10-50 \%$ SC depth $(p<0.01)$ in comparison with human SC in vivo [62]. The two depth profiles presented in Figures $1 \mathrm{~b}$ and $2 \mathrm{~b}$ correlate and show an increased content of trans conformers in the ICL chains at the depth of $20-40 \%$ SC thickness, i.e., an increase of orthorhombic organization of ICL and enhanced skin barrier function at these exemplary SC depths.

\section{Water Mobility and Hydrogen Bonding State}

The valence vibrations of the $\mathrm{OH}$ group of water originate from the broad and intense Raman band at $\approx 3,000$ $3,700 \mathrm{~cm}^{-1}$. The water concentration in the SC is nonhomogeneously distributed, increases from the surface (minimal concentration) toward the bottom of the SC (maximal concentration), and is typically calculated by the intensity ratio of the $3,350-3,550 \mathrm{~cm}^{-1}$ water-related and the 2,910-2,965 $\mathrm{cm}^{-1}$ keratin-related Raman bands [34]. This method has the main assumption that the keratin concentration in the SC is homogenously distributed. However, it has recently been shown that the concentration of keratin decreases toward the bottom of the SC [63]. The correction of the nonhomogeneous distribution of keratin results in a slightly decreased water concentration at $50-100 \%$ SC depth $(p<0.05)$, which reaches its maximum of $\approx 61.5 \%$ at the bottom of the SC [38].

In the SC water exists in different mobility states, which are determined by the strength of hydrogen bonds of water with surrounding molecules, according to the principle: strong (weak) hydrogen bonds - strongly (weakly) bound water, absence of hydrogen bonds - unbound water (UBW) [35]. The concentration of bound water in the skin can be measured using differential scanning calorimetry $[37,64]$, proton magnetic resonance $[65,66]$, and Raman spectroscopy [45]. All measurements presented in these studies were performed on skin biopsies ex vivo. In particular, water associated with ICL and keratin was a research subject in determining the limit of physiological moisturizing of the isolated SC ex vivo using Raman spectroscopy. The Raman spectrum of the SC in the region $\approx 3,100-3,700 \mathrm{~cm}^{-1}$ was decomposed using 4 Gaussian functions to determine the concentration of water mobility states [48]. The contribution of keratin in the Raman spectra was not taken into consideration.

To determine water mobility states in the SC in vivo, the contribution of keratin at $\approx 3,063$ and $\approx 3,330 \mathrm{~cm}^{-1}$ should be taken into consideration. For this reason, the decomposition in the $\approx 3,000-3,700 \mathrm{~cm}^{-1}$ region was performed using six Gaussian functions, which is presented in Figure 3a. Two Gaussian functions describe keratin (at $\approx 3,063$ and $\approx 3,330 \mathrm{~cm}^{-1}$ ) and four remaining Gaussian functions de- 

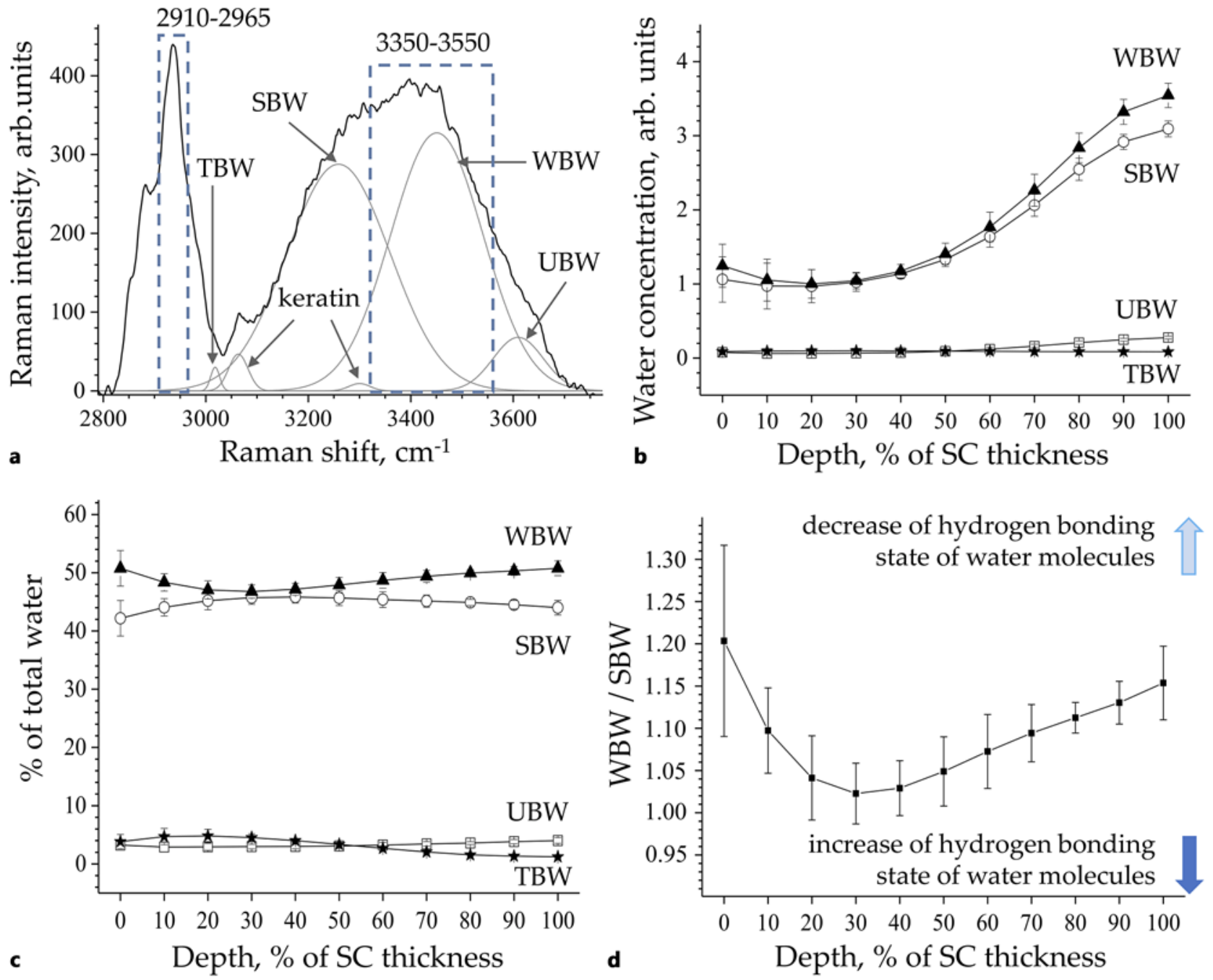

Fig. 3. Raman spectrum of human volar forearm SC (depth $20 \mu \mathrm{m}$ ) measured in vivo in the $2,790-3,775 \mathrm{~cm}^{-1}$ region and decomposed using Gaussian functions (a); the depth profile of the concentration of the water mobility states in human SC in vivo (b); the depth profile of the percentage of the water mobility states normalized by the amount of total water (c); the depth profile of the hydrogen bonding state of water molecules in the human SC in vivo (d), determined as a ratio of WBW and SBW. The SC thickness is normalized to $100 \%(0 \%-$ surface, $100 \%$ - bottom of the SC). Color in the arrows represents increase (dark blue) and decrease (light blue) of hydrogen bonding state of water molecules. Figures adopted from [59].

scribe water in different mobility states (at $\approx 3,005 \mathrm{~cm}^{-1}$ tightly-bound water [TBW]; $\approx 3,277 \mathrm{~cm}^{-1}$ - strongly-bound water [SBW]; $\approx 3,458 \mathrm{~cm}^{-1}$ - weakly-bound water [WBW]; and $\approx 3,604 \mathrm{~cm}^{-1}$ - UBW) [59], according to Sun, who performed statistical interpretation of temperature-dependent structural transitions in water [67] and showed the change of hydrogen bonding of water depending on surrounding solvents [68] using Raman spectroscopy.
Calculating the area under the corresponding Gaussian function curve for the entire SC depth provides information about the distribution of water concentrations remaining in different mobility states, depending on the strength of the hydrogen bonds in the SC (Fig. 3b). Figure $3 c$ shows the depth profile of the percent of TBW, SBW, WBW, and UBW normalized by total water content in the SC, which was calculated here as a sum of all water 

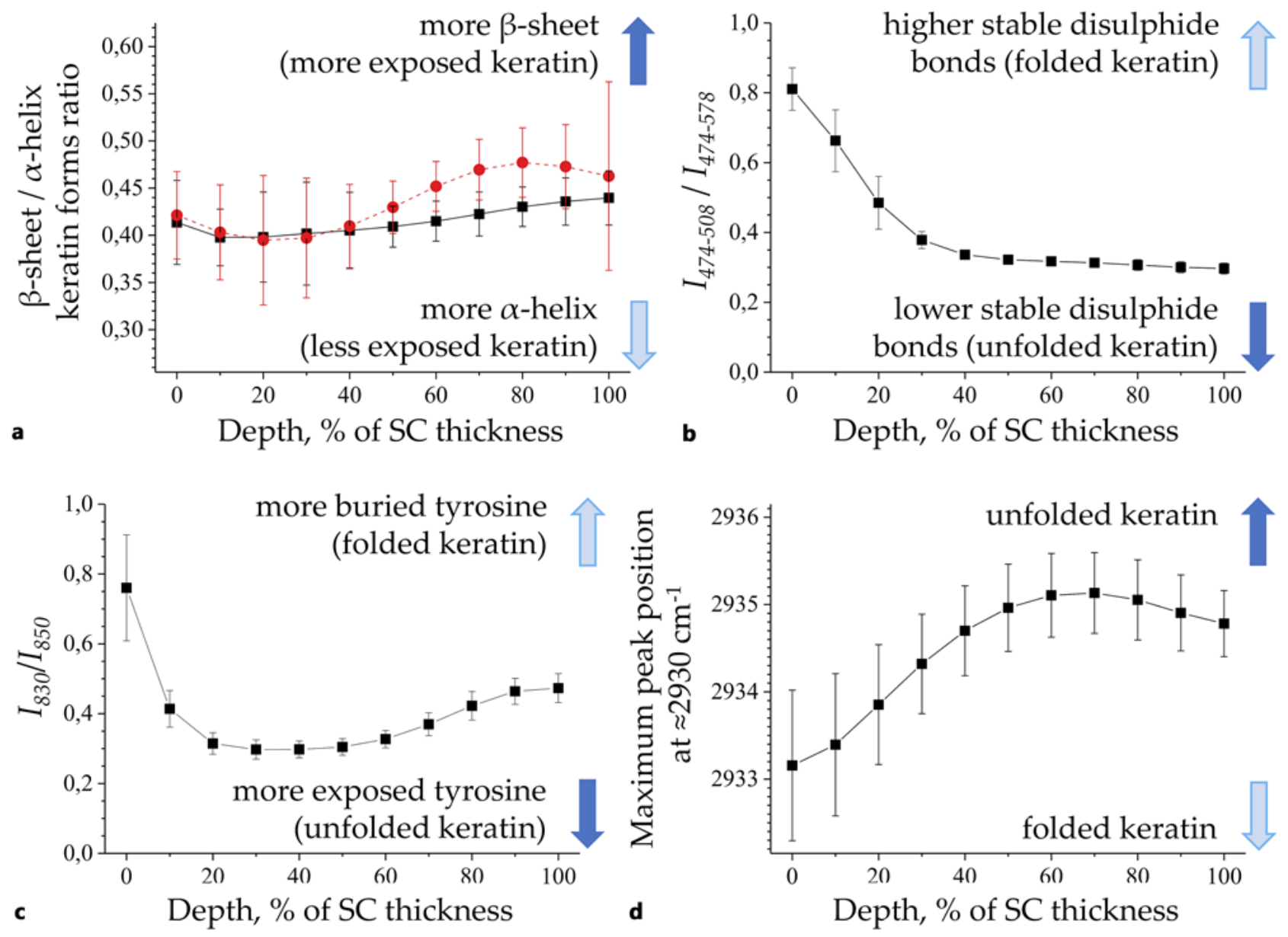

Fig. 4. The $\beta$-sheet/ $\alpha$-helix ratio measured as an $I_{960} / I_{938}$ ratio (black squares) and the ( $\beta$-sheet + turns and random coils)/ $\alpha$-helix ratio determined as an $\left(I_{1,670}+I_{1,685}\right) / I_{1,655}$ ratio of the deconvoluted Amide I band (red dotted circles) (a); the stability of disulfide bonds in keratin determined by the $I_{474-508} / I_{474-578}$ ratio of gauche-gauchegauche conformation to total disulfide bond conformations gauche-gauche-gauche + gauche-gauche-trans + trans-gauche-trans (b); buried/exposed tyrosine ratio determined by the $I_{816-838} / I_{838-874}$ ratio (c); folding state of keratin determined by the Gaussian peak position at $\approx 2,930 \mathrm{~cm}^{-1} \mathrm{SC}$ depth profiles (d). The SC thickness is normalized to $100 \%$ ( $0 \%$ - surface, $100 \%$ - bottom of the SC). Color in the arrows represents increase (dark blue) and decrease (light blue) of water molecules bonding by keratin. Figures adopted from [71].

mobility states (TBW + SBW + WBW $+\mathrm{UBW}$ ). As can be seen, SBW and WBW together represent $\geq 90 \%$, while TBW and UBW represent the remaining $\leq 10 \%$ of the total water in the SC. Figure $3 \mathrm{c}$ shows that the summation of the percentages of all water states differs from $100 \%$. This is explained by the normalization of the SC thickness to $100 \%$, which included an interpolation procedure in $10 \%$ steps, as well as intermediate averaging for all measured SC thickness values and data for all investigated areas on the skin.

Noninvasive in vivo Measurements of the Stratum Corneum
Using Raman spectroscopy Maeda and Kitano [69] determined the hydrogen bonding properties of water molecules in polymer systems analyzing a $I_{3,400} / I_{3,250}$ ratio. Thus, the WBW/SBW ratio represents a hydrogen bonding state of water molecules in the SC (Fig. 3d) - an important physiological parameter, which shows the nonhomogeneous bonding properties of water with surrounding molecules in the SC. A maximal efficacy to bind water with surrounding molecules was observed at $\approx 20$ $40 \%$ SC depth [59]. 
In older humans, these parameters are changed at exemplary SC depths toward enhancement of hydrogen bonding state of water molecules at $\approx 10-30 \%$ SC depth ( $p<0.05$ between 29 y.o. and 50 y.o. age-groups) [39]. Increase of tightly bound, unbound, and total water content in elderly skin was also reported [60]. The reduction of bound water in the SC was reported for atopic skin in vivo [61]. Porcine skin, which is widely used as an ex vivo model of human skin in dermatological research, has a lower hydrogen bonding state of water molecules at $\approx 10$ $30 \%$ SC depth $(p<0.01)$ in comparison with human SC in vivo [62].

\section{Secondary and Tertiary Structure of Keratin}

The secondary and tertiary structures of keratin are important for the regulation of water binding in the SC. The $\beta$-sheet/ $\alpha$-helix and ( $\beta$-sheet + turns and random coils)/ $\alpha$-helix ratios measured by the $I_{960} / I_{938}$ (area under the curve, $\left.I_{952-966} / I_{924-946}\right)$ and $\left(I_{1,670}+I_{1,685}\right) / I_{1,655}$ (here, the Raman band intensities $I$ are determined as area under the corresponding Gaussian curve after decomposition of the Amide I Raman band) ratios, contain information about the secondary structure of keratin. The $a$-helix is a stable form of keratin, containing a double helix and less exposed side chains, which causes a weak ability to interact with water molecules. The $\beta$-sheets contain a relatively large number of open side chains, which allow water molecules to freely penetrate between them and bind to keratin by hydrogen bonds. As shown in Figure 4a, the $\beta$-sheet/a-helix ratio is nonhomogeneous in the $\mathrm{SC}-$ decreases from the bottom (increase of the $\beta$-sheet form) toward the surface (increase of the $\alpha$-helix form) of the SC. This behavior is correlated with the conformational changes assessed using the shape of the Amide III band at $1,200-1,250 \mathrm{~cm}^{-1}$ [70] using nonnegative matrix factorization of Raman spectra.

Figure $4 \mathrm{~b}-\mathrm{d}$ show the depth distribution for the parameters describing the tertiary structure of keratin, such as stability of disulfide bonds (calculated by the $I_{474-508} / I_{474-578}$ ratio, Fig. $4 \mathrm{~b}$ ), buried/exposed configuration of tyrosine residues (calculated by the $I_{816-838} / I_{838-874}$ ratio, Fig. 4c), and the folding state of keratin (position of the Gaussian function at $\approx 2,930 \mathrm{~cm}^{-1}$ after decomposition, Fig. 4d) in the SC [71]. The results presented in Figure $4 \mathrm{~b}-\mathrm{d}$ show the nonhomogeneous distribution of the parameters describing the tertiary structure of keratin, which has a direct relation to binding of water molecules within the corneocytes.

The results shown in Figure 4 for the secondary and tertiary structures of keratin indicate that keratin is in the folded state at the superficial region $(\approx 0-30 \%$ SC depth) and, thus, unable to bind water molecules efficiently. Here, the concentration of NMF molecules is maximal [72], and they are mainly responsible for bonding water at the superficial SC region [71]. At the intermediate region ( $\approx 30-70 \%$ SC depth), concentration of NMF molecules is reduced, keratin fibers are in the unfolded state (most unfolded state is at a depth of $50-80 \%$ SC depth (Fig. 4d)) and, thus, keratin is mainly responsible for binding water molecules. In the bottom region $(\approx 80-$ $100 \%$ SC depth), the concentration of water is maximal, while the concentration of NMF molecules is minimal and bonding properties of keratin are reduced compared to the intermediate SC region (Fig. $4 \mathrm{c}, \mathrm{d}$ ). Thus, at the bottom SC region, less water is bound to keratin and NMF molecules, which is reflected in an increased concentration of UBW and WBW (Fig. 3c) as well as in a decreased hydrogen bonding state of water molecules (Fig. 3d). It appears that NMF molecules, keratin fibers as well as ICL have almost no free states and are completely saturated in the bottom region of the SC. In the case of skin occlusion, the binding of the water molecules is due to the free states of keratin, therefore an intermediate SC region determines the swelling of the SC, whereas other SC regions do not absorb water efficiently and do not swell [71]. An increased $\alpha$-helix/ $\beta$-sheet ratio (less exposed keratin) in atopic skin in vivo [61] may explain the lower water-binding properties compared to healthy skin.

In older humans, keratin is in more unfolded state compared to younger humans [39], which was recently confirmed by Rigal et al. [60]. Porcine skin, which is widely used as an ex vivo model of human skin in dermatological research, has more exposed secondary structure of keratin at $\approx 10-90 \%$ SC depth $(p<0.01)$, and a more folded tertiary structure of keratin at $\approx 30-100 \%$ SC depth $(p<0.05)$ in comparison with human SC in vivo, which determines binding of water inside the corneocytes [62].

Additionally to the composition, the noninvasive evaluation of the influence of topically applied cosmetic or medical formulations on the parameters of the SC is up to date and was previously only realized ex vivo using Raman spectroscopy [73-75]. The development of the above described algorithms allows the investigations of the influence of topically applied cosmetic or medical formulations on the components and physiological parameters of the human SC in vivo and noninvasively using confocal Raman microspectroscopy [76-79], which is in great demand for cosmetic and pharmaceutical industries. 
Determination of the SC's Components

Among most concentrated lipids, keratin, and water, characterized with strongly intense Raman bands, analysis of Raman spectra makes it possible to determine depth profiles of additional molecular components of the SC, such as NMF molecules, urocanic acid, urea, lactate [70, $72,80,81]$, as well as melanin and carotenoids [70, 82, 83]. Here, the components are evaluated using known spectral libraries [72], or without knowing their spectra using multivariate curve resolution [6] or nonnegative matrix factorization [70] statistical approaches. Carotenoids can be evaluated by their prominent Raman band at around $1,524 \mathrm{~cm}^{-1}[70,84]$; melanin can be evaluated by its Raman bands at around 1,380 and $1,570 \mathrm{~cm}^{-1}$ and by a strong fluorescence [83]. Tracking the DNA-related Raman band intensity at around $785 \mathrm{~cm}^{-1}$, it is possible to evaluate the location of the skin microbiome [85], which is observed in the superficial SC region at a depth of $0-2$ $\mu \mathrm{m}$ and is not detected at depths exceeding $4 \mu \mathrm{m}$. All these components can be determined noninvasively and in vivo in human SC.

Different algorithms in analysis of Raman spectra are proposed by many scientific groups worldwide to determine the penetration depth of topically applied formulations into the skin [70, 86-96]. These algorithms can be efficiently used to determine penetration profiles into the $\mathrm{SC}$ in vivo and ex vivo.

\section{Conclusion}

The results presented in this paper show that physiological parameters of the SC, such as lamellar and lateral organization of ICL, folding of keratin, water mobility, and hydrogen bonding states are nonhomogeneously distributed in depth and confirm that confocal Raman microspectroscopy can be successfully used for determination and analysis of physiological parameters of the human SC in vivo.

It has been shown that the skin barrier function maintained by the SC is nonhomogeneous in depth and is characterized by the strongest barrier function at $\approx 20$ $40 \%$ SC depth. In this SC region, the ICL has the highest concentration of trans conformers and orthorhombic organization, which determine skin barrier function. Analysis of the secondary and tertiary structures of keratin indicate that folding of keratin is nonhomogeneous throughout the SC: at the superficial region $(\approx 0-30 \%$ SC depth, keratin is in folded state, while at intermediate and bottom regions ( $\approx 40-100 \%$ SC depth) keratin is in more unfolded state. This behavior determines the ability of keratin to bind water molecules - water is efficiently bound by unfolded keratin. Most efficiently, keratin binds water only at the intermediate region $(\approx 30-70 \%$ SC depth), which determines swelling of the entire SC. Water in the SC is nonhomogeneously bound with SC components: the maximal bonding state of water molecules is observed at $\approx 20-40 \%$ SC depth. SBW and WBW represent together $\geq 90 \%$ of the total water in the SC. The remaining $\leq 10 \%$ of the total water in the SC is TBW and UBW. The depth-dependent inhomogeneity of the physiological parameters in the SC should be taken into consideration in planning measurements on the skin in vivo and on skin biopsies ex vivo.

\section{Conflict of Interest Statement}

The authors have no conflicts of interest to declare.

\section{Funding Sources}

This research was supported by the Foundation for Skin Physiology of the Donor Association for German Science and Humanities. Funding for C.S.C. was provided by the German Academic Exchange Service (DAAD).

\section{Author Contributions}

M.E.D., J.L., and C.S.C. planned and designed the study. J.S. and C.S.C. conceived and performed the experiments and analyzed the data. M.E.D. wrote the main manuscript text. All authors reviewed the manuscript.

\section{References}

Skin Pharmacol Physiol 2022;35:125-136

1 Lademann J, Meinke MC, Schanzer S, Richter $H$, Darvin ME, Haag SF, et al. In vivo methods for the analysis of the penetration of topically applied substances in and through the skin barrier. Int J Cosmet Sci. 2012 Dec;34(6):5519.

2 Evora AS, Adams MJ, Johnson SA, Zhang Z. Corneocytes: relationship between structural and biomechanical properties. Skin Pharmacol Physiol. 2021;34(3):146-61.

3 Lazo ND, Meine JG, Downing DT. Lipids are covalently attached to rigid corneocyte protein envelopes existing predominantly as beta-sheets: a solid-state nuclear magnetic resonance study. J Invest Dermatol. 1995 Aug; 105(2):296-300. 
4 Elias PM, Gruber R, Crumrine D, Menon G, Williams ML, Wakefield JS, et al. Formation and functions of the corneocyte lipid envelope (CLE). Biochim Biophys Acta Biomembranes Mol Cell Biol Lipids. 2014 Mar; 1841(3):314-8.

5 Proksch E, Jensen JM. Skin as an organ of protection. In: Goldsmith LA, Katz SI, Gilchrest BA, Paller AS, Leffell DJ, Wolff K, editors. Fitzpatrick's dermatology in general medicine, 8e. New York: McGraw-Hill; 2008.

6 Zhang LS, Cambron T, Niu YQ, Xu ZG, Su N, Zheng HY, et al. MCR approach revealing protein, water, and lipid depth profile in atopic dermatitis patients' stratum corneum via in vivo confocal Raman spectroscopy. Anal Chem. 2019 Feb 19;91(4):2784-90.

7 Wertz P. Epidermal lamellar granules. Skin Pharmacol Physiol. 2018;31(5):262-8.

8 Weerheim A, Ponec M. Determination of stratum corneum lipid profile by tape stripping in combination with high-performance thin-layer chromatography. Arch Dermatol Res. 2001 Apr;293(4):191-9.

9 Norlen L. Current understanding of skin barrier morphology. Skin Pharmacol Physiol. 2013;26(4-6):213-6.

10 Boncheva $\mathrm{M}$. The physical chemistry of the stratum corneum lipids. Int J Cosmet Sci. 2014 Dec;36(6):505-15.

11 Schmitt T, Neubert RHH. State of the art in stratum corneum research. Part II: hypothetical stratum corneum lipid matrix models. Skin Pharmacol Physiol. 2020 Jul 17;33:21330.

12 Madison KC, Swartzendruber DC, Wertz PW, Downing DT. Presence of intact intercellular lipid lamellae in the upper layers of the stratum corneum. J Invest Dermatol. 1987 Jun;88(6):714-8

13 Masukawa Y, Narita H, Shimizu E, Kondo N, Sugai Y, Oba T, et al. Characterization of overall ceramide species in human Stratum corneum. J Lipid Res. 2008 Jul;49(7):1466-76.

14 Swartzendruber DC, Wertz PW, Kitko DJ, Madison KC, Downing DT. Molecular models of the intercellular lipid lamellae in mammalian stratum corneum. J Invest Dermatol. 1989 Feb;92(2):251-7.

15 Bouwstra JA, Gooris GS, van der Spek JA, Bras W. Structural investigations of human stratum corneum by small-angle X-ray scattering. J Invest Dermatol. 1991 Dec;97(6): 1005-12.

16 Kuempel D, Swartzendruber DC, Squier CA, Wertz PW. In vitro reconstitution of stratum corneum lipid lamellae. Biochim Biophys Acta. 1998 Jun 24;1372(1):135-40.

17 Hill JR, Wertz PW. Molecular models of the intercellular lipid lamellae from epidermal stratum corneum. Biochim Biophys Acta. 2003 Oct 13;1616(2):121-6.

18 van Smeden J, Janssens M, Gooris GS, Bouwstra JA. The important role of stratum corneum lipids for the cutaneous barrier function. Biochim Biophys Acta. 2014 Mar; 1841(3):295-313.
19 Bouwstra JA, Dubbelaar FE, Gooris GS, Ponec M. The lipid organisation in the skin barrier. Acta Derm Venereol Suppl. 2000;208: 23-30.

20 Kiselev MA, Ryabova NY, Balagurov AM, Dante S, Hauss T, Zbytovska J, et al. New insights into the structure and hydration of a stratum corneum lipid model membrane by neutron diffraction. Eur Biophys J. 2005 Nov; 34(8):1030-40.

21 Schroter A, Kessner D, Kiselev MA, Hauss T, Dante S, Neubert RH. Basic nanostructure of stratum corneum lipid matrices based on ceramides [EOS] and [AP]: a neutron diffraction study. Biophys J. 2009 Aug 19;97(4): 1104-14.

22 Iwai I, Han HM, den Hollander L, Svensson S, Ofverstedt LG, Anwar J, et al. The human skin barrier is organized as stacked bilayers of fully extended ceramides with cholesterol molecules associated with the ceramide sphingoid moiety. J Invest Dermatol. 2012 Sep;132(9):2215-25.

23 Doucet J, Potter A, Baltenneck C, Domanov YA. Micron-scale assessment of molecular lipid organization in human stratum corneum using microprobe $\mathrm{X}$-ray diffraction. J Lipid Res. 2014 Nov;55(11):2380-8.

24 Bouwstra JA, Gooris GS. The lipid organisation in human stratum corneum and model systems. Todj. 2010;4(1):10-3.

25 Janssens M, van Smeden J, Gooris GS, Bras W, Portale G, Caspers PJ, et al. Increase in shortchain ceramides correlates with an altered lipid organization and decreased barrier function in atopic eczema patients. J Lipid Res. 2012 Dec;53(12):2755-66.

26 Pilgram GSK, Pelt AMEV, Oostergetel GT, Koerten HK, Bouwstra JA. Study on the lipid organization of stratum corneum lipid models by (cryo-) electron diffraction. J Lipid Res. 1998 Aug;39(8):1669-76.

27 van Smeden J, Boiten WA, Hankemeier T, Rissmann R, Bouwstra JA, Vreeken RJ. Combined LC/MS-platform for analysis of all major stratum corneum lipids, and the profiling of skin substitutes. Biochim Biophys Acta. 2014 Jan; 1841(1):70-9.

28 Quatela A, Tfayli A, Baillet-Guffroy A. Examination of the effect of stratum corneum isolation process on the integrity of the barrier function: a confocal Raman spectroscopy study. Skin Res Technol. 2016 Feb;22(1):7580.

29 Berardesca E, Fideli D, Borroni G, Rabbiosi G, Maibach $\mathrm{H}$. In vivo hydration and water-retention capacity of stratum corneum in clinically uninvolved skin in atopic and psoriatic patients. Acta Derm Venereol. 1990;70(5): 400-4.

30 Sator PG, Schmidt JB, Hönigsmann H. Comparison of epidermal hydration and skin surface lipids in healthy individuals and in patients with atopic dermatitis. J Am Acad Dermatol. 2003 Mar;48(3):352-8.
31 Sahle FF, Gebre-Mariam T, Dobner B, Wohlrab J, Neubert RH. Skin diseases associated with the depletion of stratum corneum lipids and stratum corneum lipid substitution therapy. Skin Pharmacol Physiol. 2015;28(1):4255.

32 Vyumvuhore R, Michael-Jubeli R, Verzeaux L, Boudier D, Le Guillou M, Bordes S, et al. Lipid organization in xerosis: the key of the problem? Int J Cosmet Sci. 2018 Dec;40(6): 549-54.

33 Bow JR, Sonoki Y, Uchiyama M, Shimizu E, Tanaka K, Dauskardt RH. Lipid loss increases stratum corneum stress and drying rates. Skin Pharmacol Physiol. 2020;33(4):180-8.

34 Caspers PJ, Lucassen GW, Bruining HA, Puppels GJ. Automated depth-scanning confocal Raman microspectrometer for rapid in vivo determination of water concentration profiles in human skin. J Raman Spectrosc. 2000 AugSep;31(8-9):813-8.

35 Scheuplein RJ, Morgan LJ. "Bound water" in keratin membranes measured by a microbalance technique. Nature. 1967 Apr 29; 214(5087):456-8.

36 Rawlings AV, Harding CR. Moisturization and skin barrier function. Dermatol Ther. 2004;17 Suppl 1(Suppl 1):43-8.

37 Imokawa G, Kuno H, Kawai M. Stratum corneum lipids serve as a bound-water modulator. J Invest Dermatol. 1991 Jun;96(6):84551.

38 Darvin ME, Choe CS, Schleusener J, Lademann J. Non-invasive depth profiling of the stratum corneum in vivo using confocal Raman microscopy considering the non-homogeneous distribution of keratin. Biomed Opt Express. 2019 Jun 1;10(6):3092-103.

39 Choe C, Schleusener J, Lademann J, Darvin ME. Age related depth profiles of human stratum corneum barrier-related molecular parameters by confocal Raman microscopy in vivo. Mech Ageing Dev. 2018 Jun;172:6-12.

40 Hussain H, Ziegler J, Hause G, Wohlrab J, Neubert RHH. Quantitative analysis of free amino acids and urea derived from isolated corneocytes of healthy young, healthy aged, and diseased skin. Skin Pharmacol Physiol. 2019;32(2):94-100.

41 Lademann J, Patzelt A, Darvin M, Richter H, Antoniou C, Sterry W, et al. Application of optical non-invasive methods in skin physiology. Las Phys Lett. 2008 May;5(5):335-46.

42 Darvin ME, Richter H, Zhu YJ, Meinke MC, Knorr F, Gonchukov SA, et al. Comparison of in vivo and ex vivo laser scanning microscopy and multiphoton tomography application for human and porcine skin imaging. Quantum Electronics. 2014;44(7):646-51.

43 Czekalla C, Schönborn KH, Lademann J, Meinke MC. Noninvasive determination of epidermal and stratum corneum thickness in vivo using two-photon microscopy and optical coherence tomography: impact of body area, age, and gender. Skin Pharmacol Physiol. 2019;32(3):142-50. 
44 Dong P, Nikolaev V, Kroger M, Zoschke C, Darvin ME, Witzel C, et al. Barrier-disrupted skin: quantitative analysis of tape and cyanoacrylate stripping efficiency by multiphoton tomography. Int J Pharm. 2020 Jan 25;574: 118843.

45 Gniadecka M, Faurskov Nielsen O, Christensen DH, Wulf HC. Structure of water, proteins, and lipids in intact human skin, hair, and nail. J Invest Dermatol. 1998 Apr;110(4): 393-8.

46 Gaber BP, Peticolas WL. On the quantitative interpretation of biomembrane structure by Raman spectroscopy. Biochim Biophys Acta. 1977 Mar 1;465(2):260-74.

47 Tfayli A, Guillard E, Manfait M, Baillet-Guffroy A. Raman spectroscopy: feasibility of in vivo survey of stratum corneum lipids, effect of natural aging. Eur J Dermatol. 2012 JanFeb;22(1):36-41.

48 Vyumvuhore R, Tfayli A, Duplan H, Delalleau A, Manfait M, Baillet-Guffroy A. Effects of atmospheric relative humidity on stratum corneum structure at the molecular level: ex vivo Raman spectroscopy analysis. Analyst. 2013 Jul 21;138(14):4103-11.

49 Kikuchi S, Aosaki T, Bito K, Naito S, Katayama Y. In vivo evaluation of lateral lipid chain packing in human stratum corneum. Skin Res Technol. 2015 Feb;21(1):76-83.

50 Tfayli A, Guillard E, Manfait M, Baillet-Guffroy A. Thermal dependence of Raman descriptors of ceramides. Part I: effect of double bonds in hydrocarbon chains. Anal Bioanal Chem. 2010 Jun;397(3):1281-96.

51 Guillard E, Tfayli A, Manfait M, Baillet-Guffroy A. Thermal dependence of Raman descriptors of ceramides. Part II: effect of chains lengths and head group structures. Anal Bioanal Chem. 2011 Jan;399(3):1201-13.

52 Wallach DF, Verma SP, Fookson J. Application of laser Raman and infrared spectroscopy to the analysis of membrane structure. Biochim Biophys Acta. 1979 Aug 20;559(2-3): 153-208.

53 Sagitova EA, Donfack P, Nikolaeva GY, Prokhorov KA, Zavgorodnev YV, Pashinin $\mathrm{PP}$, et al. Regularity modes in Raman spectra of polyolefins: Part II. polyethylene and ethylene copolymers. Vibr Spectroscopy. 2016 May;84:139-45.

54 Choe C, Lademann J, Darvin ME. A depthdependent profile of the lipid conformation and lateral packing order of the stratum corneum in vivo measured using Raman microscopy. Analyst. 2016 Mar 21;141(6):1981-7.

55 Boncheva M, Damien F, Normand V. Molecular organization of the lipid matrix in intact stratum corneum using ATR-FTIR spectroscopy. Biochim Biophys Acta. 2008 May; 1778(5):1344-55.

56 Percot A, Lafleur M. Direct observation of domains in model stratum corneum lipid mixtures by Raman microspectroscopy. Biophys J. 2001 Oct;81(4):2144-53.
57 Osada M, Gniadecka M, Wulf HC. Near-infrared Fourier transform Raman spectroscopic analysis of proteins, water and lipids in intact normal stratum corneum and psoriasis scales. Exp Dermatol. 2004 Jun;13(6):391-5.

58 Caussin J, Gooris GS, Janssens M, Bouwstra JA. Lipid organization in human and porcine stratum corneum differs widely, while lipid mixtures with porcine ceramides model human stratum corneum lipid organization very closely. Biochim Biophys Acta. 2008 Jun; 1778(6):1472-82.

59 Choe C, Lademann J, Darvin ME. Depth profiles of hydrogen bound water molecule types and their relation to lipid and protein interaction in the human stratum corneum in vivo. Analyst. 2016 Nov 21;141(22):6329-37.

60 Rigal A, Michael-Jubeli R, Nkengne A, Baillet-Guffroy A, Bigouret A, Tfayli A. Raman confocal microscopy and biophysics multiparametric characterization of the skin barrier evolution with age. J Biophotonics. 2021; 14(9):e202100107.

61 Verzeaux L, Vyumvuhore R, Boudier D, Le Guillou M, Bordes S, Essendoubi M, et al. Atopic skin: in vivo Raman identification of global molecular signature, a comparative study with healthy skin. Exp Dermatol. 2018 Apr;27(4):403-8.

62 Choe C, Schleusener J, Lademann J, Darvin ME. Human skin in vivo has a higher skin barrier function than porcine skin ex vivocomprehensive Raman microscopic study of the stratum corneum. J Biophotonics. 2018 Jun;11(6):e201700355.

63 Choe C, Choe S, Schleusener J, Lademann J, Darvin ME. Modified normalization method in in vivo stratum corneum analysis using confocal Raman microscopy to compensate nonhomogeneous distribution of keratin. J Raman Spectrosc. 2019 Jul;50(7):945-57.

64 Walkley K. Bound water in stratium corneum measured by differential scanning calorimetry. J Invest Dermatol. 1972;59(3):225-7.

65 Yamamura T, Tezuka T. The water-holding capacity of the stratum corneum measured by 1H-NMR. J Invest Dermatol. 1989 Jul;93(1): 160-4.

66 Gilard V, Martino R, Malet-Martino M, Riviere M, Gournay A, Navarro R. Measurement of total water and bound water contents in human stratum corneum by in vitro proton nuclear magnetic resonance spectroscopy. Int J Cosmet Sci. 1998 Apr;20(2):117-25.

67 Sun Q. Local statistical interpretation for water structure. Chemical Physics Letters. 2013 May 1;568-9:90-4.

68 Li D, Zhu Z, Sun DW. Quantification of hydrogen bonding strength of water in saccharide aqueous solutions by confocal Raman microscopy. J Mol Liq. 2021;342:117498.

69 Maeda Y, Kitano H. The structure of water in polymer systems as revealed by Raman spectroscopy. Spectrochim Acta Part A. 1995 Dec; 51(14):2433-46.
70 Yakimov BP, Venets AV, Schleusener J, Fadeev VV, Lademann J, Shirshin EA, et al. Blind source separation of molecular components of the human skin in vivo: non-negative matrix factorization of Raman microspectroscopy data. Analyst. 2021;146(10):318596.

71 Choe C, Schleusener J, Lademann J, Darvin ME. Keratin-water-NMF interaction as a three layer model in the human stratum corneum using in vivo confocal Raman microscopy. Sci Rep. 2017 Nov 21;7(1):15900.

72 Caspers PJ, Lucassen GW, Carter EA, Bruining HA, Puppels GJ. In vivo confocal Raman microspectroscopy of the skin: noninvasive determination of molecular concentration profiles. J Invest Dermatol. 2001 Mar;116(3): 434-42.

73 Zhang Z, Lunter DJ. Confocal Raman microspectroscopy as an alternative to differential scanning calorimetry to detect the impact of emulsifiers and formulations on stratum corneum lipid conformation. Eur J Pharm Sci. 2018 Aug 30;121:1-8.

74 Fujii MY, Gato K, Ozawa Y, Hisada H, Koide T, Inoue $\mathrm{M}$, et al. In situ monitoring of lipid phase state make target lipid mixtures similar to intercellular lipid in the stratum corneum. Eur J Lipid Sci Tech. 2020 Mar;122(3):1900171.

75 Liu Y, Lunter DJ. Tracking heavy-water-incorporated confocal Raman spectroscopy for evaluating the effects of PEGylated emulsifiers on skin barrier. J Biophotonics. 2020 Dec; 13(12):e202000286.

76 Choe C, Schleusener J, Lademann J, Darvin ME. In vivo confocal Raman microscopic determination of depth profiles of the stratum corneum lipid organization influenced by application of various oils. J Dermatol Sci. 2017 Aug;87(2):183-91.

77 Choe C, Schleusener J, Choe S, Lademann J, Darvin ME. A modification for the calculation of water depth profiles in oil-treated skin by in vivo confocal Raman microscopy. J Biophotonics. 2020 Jan;13(1):e201960106.

78 Choe C, Schleusener J, Choe S, Ri J, Lademann J, Darvin ME. Stratum corneum occlusion induces water transformation towards lower bonding state: a molecular level in vivo study by confocal Raman microspectroscopy. Int J Cosmet Sci. 2020 Jul 21;42:482-93.

79 Schleusener J, Salazar A, von Hagen J, Lademann J, Darvin ME. Retaining skin barrier function properties of the stratum corneum with components of the natural moisturizing factor-A randomized, Placebo-Controlled Double-Blind In Vivo Study. Molecules. 2021 Mar 16;26(6):1649.

80 Caspers PJ, Lucassen GW, Wolthuis R, Bruining HA, Puppels GJ. In vitro and in vivo Raman spectroscopy of human skin. Biospectroscopy. 1998;4(5):S31-9.

81 Vyumvuhore R, Tfayli A, Piot O, Le Guillou M, Guichard N, Manfait M, et al. Raman spectroscopy: in vivo quick response code of skin physiological status. J Biomed Opt. 2014; 19(11):111603. 
82 Lademann J, Caspers PJ, van der Pol A, Richter $\mathrm{H}$, Patzelt A, Zastrow L, et al. In vivo Raman spectroscopy detects increased epidermal antioxidative potential with topically applied carotenoids. Las Phys Lett. 2009 Jan; 6(1):76-9.

83 Yakimov BP, Shirshin EA, Schleusener J, Allenova AS, Fadeev VV, Darvin ME. Melanin distribution from the dermal-epidermal junction to the stratum corneum: non-invasive in vivo assessment by fluorescence and Raman microspectroscopy. Sci Rep. 2020 Sep 1;10(1): 14374.

84 Choe C, Ri J, Schleusener J, Lademann J, Darvin ME. The non-homogenous distribution and aggregation of carotenoids in the stratum corneum correlates with the organization of intercellular lipids in vivo. Exp Dermatol. 2019 Nov;28(11):1237-43.

85 Ri JS, Choe SH, Schleusener J, Lademann J, Choe CS, Darvin ME. In vivo tracking of DNA for precise determination of the stratum corneum thickness and superficial microbiome using confocal Raman microscopy. Skin Pharmacol Physiol. 2020;33(1):30-7.

86 Choe C, Lademann J, Darvin ME. Analysis of human and porcine skin in vivo/ex vivo for penetration of selected oils by confocal Ra- man microscopy. Skin Pharmacol Physiol. 2015;28(6):318-30.

87 Zhu Y, Choe CS, Ahlberg S, Meinke MC, Alexiev U, Lademann J, et al. Penetration of silver nanoparticles into porcine skin ex vivo using fluorescence lifetime imaging microscopy, Raman microscopy, and surface-enhanced Raman scattering microscopy. J Biomed Opt. 2015 May;20(5):051006.

88 Essendoubi M, Gobinet C, Reynaud R, Angiboust JF, Manfait M, Piot O. Human skin penetration of hyaluronic acid of different molecular weights as probed by Raman spectroscopy. Skin Res Technol. 2016 Feb;22(1): $55-62$.

89 Lunter DJ. Determination of skin penetration profiles by confocal Raman microspectroscopy: statistical evaluation of optimal microscope configuration. J Raman Spectrosc. 2017 Feb;48(2):152-60.

90 Tippavajhala VK, de Oliveira Mendes T, Martin AA. In vivo human skin penetration study of sunscreens by confocal Raman spectroscopy. AAPS PharmSciTech. 2018 Feb;19(2):753-60.

91 Caspers PJ, Nico C, Bakker Schut TC, de Sterke J, Pudney PDA, Curto PR, et al. Method to quantify the in vivo skin penetration of topically applied materials based on confocal Ra- man spectroscopy. Translational Biophotonics. 2019;1:e201900004.

92 Binder L, Valenta C, Lunter D. Determination of skin penetration profiles by confocal Raman microspectroscopy: evaluation of interindividual variability and interlab comparability. J Raman Spectrosc. 2020 Jul;51(7): 1037-43.

93 Krombholz R, Lunter D. A new method for in-situ skin penetration analysis by confocal Raman microscopy. Molecules. 2020 Sep 15; 25(18):4222.

94 Stella A, Bonnier F, Tfayli A, Yvergnaux F, Byrne HJ, Chourpa I, et al. Raman mapping coupled to self-modelling MCR-ALS analysis to estimate active cosmetic ingredient penetration profile in skin. J Biophotonics. 2020;13: e202000136.

95 Essendoubi M, Alsamad F, Noël P, Meunier M, Scandolera A, Sandré J, et al. Combining Raman imaging and MCR-ALS analysis for monitoring retinol permeation in human skin. Skin Res Technol. 2021 Jun 11;51(7): 1037-43.

96 Krombholz R, Liu Y, Lunter DJ. In-line and off-line monitoring of skin penetration profiles using confocal Raman spectroscopy. Pharmaceutics. 2021;13(1):67. 